\title{
PROPOSIÇÃO DE MELHORIAS EM SEGURANÇA POR MEIO DA APLICAÇÃO DO FMEA: UM ESTUDO DE CASO EM UMA EMPRESA DO SETOR FERROVIÁRIO
}

\author{
Josemar Coelho Félix ${ }^{1}$, Cristiane de Fatima Batista Alves ${ }^{1}$, Scheila Cardoso Albuquerque ${ }^{1}$, Natânia Cristina Santana Santos ${ }^{1}$, \\ Leandro César Mol Barbosa ${ }^{1}$ \\ 1 Curso de Engenharia de Produção do Instituto Federal de Minas Gerais - IFMG -36415-000, Congonhas, Brasil.
}

*E-mail: felix.josemar@gmail.com

Recebido em:09/01/2018

Aceito em:06/06/2018

\begin{abstract}
RESUMO
Este artigo apresenta um estudo de caso voltado à aplicação da ferramenta Failure Modes and Effects Analysis (FMEA) em uma empresa do setor ferroviário, com o objetivo de levantar as principais práticas inseguras nas atividades de manutenção de vagões. Para tal, a abordagem aqui adotada incluiu uma revisão histórica da evolução da segurança do trabalho e da manutenção no Brasil, bem como a utilização do FMEA na prática de serviços. A partir da aplicação do FMEA, foi realizada uma análise das atividades inseguras na manutenção de vagões da empresa, identificando funções de risco e foram expostas propostas de intervenções de um grupo de pesquisadores acadêmicos. Os resultados identificaram pontos críticos de falha nas práticas, os quais posteriormente podem ser analisados para determinação de estratégias de melhorias, a fim de maximizar a segurança dos trabalhadores e garantir a confiabilidade dos serviços. Concluiu-se que a ferramenta FMEA é útil para o mapeamento de atitudes que comprometem a integridade física do trabalhador e que o comportamento é o ponto mais importante a ser abordado nas propostas de segurança do trabalho.
\end{abstract}

Palavras chave: Segurança do Trabalho; FMEA; Manutenção.

\section{Introdução}

Para a logística, o transporte representa uma atividade de grande importância, uma vez que detém uma parcela expressiva dos custos de uma empresa. Sabendo-se que o cenário atual dos meios de transporte no Brasil ainda se apresenta muito deficiente, o que resulta em um aumento acentuado do preço final dos produtos transportados, nota-se a necessidade de reorganização do sistema e ampliação da concorrência de mercado, tendo em vista o desenvolvimento do país [1].

O setor ferroviário no Brasil é focado no transporte de produtos de grande volume, porém de baixo valor agregado, representando a melhor opção logística para esta categoria. Este setor é formado por diversas empresas envolvidas e interessadas na melhoria e expansão de suas atividades, sendo necessário para isto grandes investimentos e avanços. Estes avanços se tornam mais críticos para o país uma vez que estão vinculados a exportação [2].

Devido à falta de investimentos e progressos no setor ferroviário, a manutenção dos veículos de transporte tem papel importante na eficiência operacional e está relacionada ao potencial de produção das empresas como um todo. Ela visa prever as condições dos equipamentos para obter melhorias contínuas para os procedimentos operacionais, garantir a disponibilidade e a confiabilidade do processo. A manutenção realizada nas oficinas ferroviárias mantém os maquinários conservados, garantindo a integridade e a vida útil dos equipamentos [3].

É importante estabelecer estratégias para alcançar os melhores resultados no mercado ferroviário. Um bom planejamento voltado para a manutenção garante um diferencial competitivo que, se combinado a estratégias de confiabilidade, pode resultar no sucesso da organização.

Deve-se ressaltar ainda que o setor de manutenção é fundamental nas empresas e este deve manter a limpeza, a organização e a segurança do ambiente de trabalho. Essas atitudes são importantes para elevar a qualidade dos serviços, a competitividade da empresa e resguardar a integridade física dos trabalhadores. Tais condições devem estar alinhadas com a gestão, e para que elas sejam realmente tratadas com prioridade é imprescindível que a preservação da vida do trabalhador faça parte dos valores das empresas.

Nesse contexto, o objetivo deste estudo é encontrar as principais práticas inseguras no trabalho de manutenção do material rodante (vagões), mostrando a importância da segurança no trabalho em manutenção, bem como evidenciar as principais atividades e práticas inseguras na manutenção. Além disso, o artigo também visa destacar a partir de observações sistemáticas, a função que mais realiza práticas inseguras e que, por sua vez, representa uma maior possibilidade de prejudicar à integridade física do mantenedor. Para isso será utilizada a 
ferramenta FMEA, no intuito de priorizar e propor medidas de melhoria.

\subsection{A história da manutenção e da segurança do trabalho no Brasil}

A manutenção como conhecida hoje se consolidou no período da revolução industrial pela necessidade de realizar reparos em equipamentos e máquinas de maior porte. Devido ao desgaste e quebra dos instrumentos e equipamentos, a manutenção era vista como um mal necessário às atividades industriais. Hoje, além de preservar sistemas produtivos, segundo Nepomucenu [4], a manutenção visa o planejamento de programas coerentes de reparo que minimizem os custos e realizem intervenções em um menor prazo. A NBR ISO 55000 [5], ainda ressalta a evolução da integração entre a manutenção e as atividades de gestão de ativos nas empresas.

A manutenção é definida por Seleme [6] como a "combinação de ações e técnicas administrativas que buscam manter ou realocar um item em um estado no qual possa desempenhar uma função requerida". Além disso, as atividades de manutenção visam ainda a prevenção de falhas e recuperação de um item. Kardec e Nascif [7] em 2007 classificam a manutenção em corretiva, corretiva não planejada, corretiva planejada, preventiva e preditiva.

No que tange à segurança, esta vem sendo um fator de preocupação desde os tempos em que os ferramentais passaram a fazer parte do trabalho. Nos primórdios, o homem já apresentava cuidados com segurança voltados a sobrevivência e proteção da espécie sendo que, mais tarde, o trabalho foi associado ao surgimento de doenças. Hipócrates 460 a.C, conhecido como pai da medicina, relatou o envenenamento de trabalhadores por chumbo, durante a extração do metal. Já Plínio (23-79 d.C.), descreveu as condições de trabalho nas minas e os agentes mais nocivos, buscando assegurar as condições mínimas de trabalho [8]. Na idade média, estudos revelaram a utilização de máscaras de proteção durante a atividade mineradora para minimizar as doenças pulmonares. Nos séculos XII e XIII os processos produtivos passaram por mudanças significativas, levando ao relato de acidentes do trabalho e doenças profissionais desconhecidas até então. As mudanças trazidas pela revolução industrial acarretaram consigo o aumento do uso de máquinas, o acúmulo de operários em locais fechados, a submissão a longas jornadas de trabalho, bem como péssimas condições de salubridade dos ambientes, resultando na precarização da saúde dos trabalhadores. A partir de 1770 deuse origem aos primeiros livros de medicina do trabalho e a sistematização da tratativa de doenças profissionais [9].

Com relação ao Brasil, durante o período colonial e imperial, a maior parte do trabalho era realizada por escravos e/ou homens livres pobres sem que houvesse uma preocupação com saúde e segurança. A legislação de proteção aos trabalhadores surgiu durante a República Velha e foi ampliada no Governo Vargas em 1930 com a Consolidação das Leis Trabalhistas, sendo atualizada pela Constituição da República Federativa do Brasil em 1988 Hoje, através da fundação Jorge Duprat Figueiredo de Segurança e Medicina do Trabalho (Fundacentro), o Brasil realiza pesquisa em segurança, higiene, meio ambiente e medicina do trabalho como forma de normatização do campo. Além disso, foram elaboradas pelo Ministério do Trabalho as Normas Regulamentadoras (NR's), no intuito de promover uma adequação das condições de trabalho, dos riscos ocupacionais e das medidas de controle. As NR's são a base de fiscalização dos ambientes de trabalho e buscam identificar e quantificar os fatores de riscos, além de verificar a formalização de contratos, jornadas e períodos de descanso [10].

Diante deste contexto, é importante ressaltar a constante necessidade das instituições em atentar-se para as diretrizes políticas, de forma que consigam cumprir efetivamente suas responsabilidades [11].

\subsection{A importância da segurança do trabalho na manutenção}

A manutenção tem sua importância na conservação dos bens e recursos de uma empresa e na garantia da confiabilidade adequada do processo. Em paralelo, a segurança do trabalho, além de manter a integridade física do trabalhador, também confere proteção ao investimento e aos lucros provenientes do processo. Como efeito desta dualidade, tem-se a valorização da segurança operacional pela empresa, onde esta a elabora, atualiza e disponibiliza em forma de procedimentos operacionais e recursos de segurança como EPI's (Equipamentos de Proteção Individual) e EPC's (Equipamentos de Proteção Coletiva) [12].

Segundo a Lei $\mathrm{n}^{\circ} 6.514$ [13], cabe às empresas verificar se estão sendo cumpridas todas as normas de segurança e medicina do trabalho em suas dependências. As organizações devem instruir os empregados e criar documentos que detalhem as formas de se evitar acidentes do trabalho ou doenças ocupacionais. Não obstante, cabe ao funcionário colaborar com a empresa na aplicação dos dispositivos colocados pela lei como essenciais à preservação da vida. Para tal, tanto as empresas quanto os empregados devem se orientar pelas Normas Regulamentadoras, sendo estas de observâncias obrigatórias para qualquer tipo de empresa ou organização que possua empregados regidos pela Consolidação das Leis do Trabalho CLT [14]. Vale ressaltar que, anteriormente à criação das Normas Regulamentadoras em 1978, estudos já haviam sido realizados nos Estados Unidos da América onde, em uma análise de 297 companhias, envolvendo cerca de 170 mil pessoas, foram quantificados 1.753.498 acidentes. Estes dados resultaram na criação da pirâmide de Frank Bird, que ressalta a relação direta entre incidentes sem danos pessoais/materiais e acidentes, em uma relação de 600 para 1 respectivamente [15].

\subsection{O erro humano e os atos inseguros}


De acordo com Miguel [16], em sua abordagem teórica da literatura relativa às causas de acidentes, é ressaltado o fenômeno do efeito dominó. Este fenômeno se caracteriza pela relação de precedência entre um ato e outro na geração de uma falha (acidente), sendo a causa ou motivo do erro humano, a sua fonte primária. Este conceito que caracterizou o ato inseguro do trabalhador, foi difundido durante o "milagre econômico" por órgãos oficiais e vem sofrendo duras críticas por eximir as empresas de suas responsabilidades no que tange aos acidentes de trabalho [17]. O termo "ato inseguro" foi retirado das Normas Regulamentadoras, uma vez que este favorece a imputação de culpa ao trabalhador no caso de acidentes, questão esta veementemente criticada por importantes autores do campo [18].

Reason [19], afirma que a ocorrência de um erro humano, não pode ser classificada como uma falha. Esta representa a soma de fatores que devem ser devidamente investigados. $\mathrm{O}$ autor ainda ressalta que tais práticas inseguras são o resultado de ineficiências do sistema, problemas de layout ou até da má gestão praticada no ambiente empresarial. Desta forma, as empresas se veem obrigadas a tomar medidas para evitar acidentes, investindo nos fatores que levam a estas práticas.

Sendo assim, o reconhecimento e desenvolvimento de ações para a tratativa dos fatores que levam aos acidentes devem ser verificados de forma minuciosa por parte das empresas, uma vez que estas não podem se eximir de suas responsabilidades. Os meios pelos quais o indivíduo se expõe aos riscos devem ser devidamente investigados em seu sentido mais amplo. Segundo Reason [20], para que uma análise seja realizada de forma adequada, estas falhas devem ser organizadas e classificadas, justificando a utilização de ferramentas como o FMEA.

\subsection{O FMEA e sua utilização na prática do serviço}

Embora originalmente criada para o desenvolvimento de novos produtos, o FMEA vem sendo amplamente aplicado na indústria, no intuito de melhorar a qualidade dos processos produtivos [21]. Fogliatto e Ribeiro [22], afirmam que a melhoria da qualidade do processo é essencial para o desempenho da organização, sendo o FMEA uma ferramenta reconhecida para tal. Como uma técnica de confiabilidade e a fim de possibilitar a garantia da qualidade dos processos, o FMEA revela as ineficiências do sistema, se mostrando significativa aos seus usuários, devido sua capacidade de apresentar e eliminar possíveis ocorrências de falhas. Esta ferramenta é importante pois auxilia na melhoria contínua do processo, uma vez que as análises ocorrem de forma cíclica e sistemática. $\mathrm{O}$ ator ainda afirma que as investigações devem ser documentadas para que o processo de eliminação de falhas seja realmente eficiente, ampliando ainda mais a importância de sua utilização.

Um bom exemplo da aplicação do FMEA está relacionado ao desenvolvimento de células a combustível, em que são analisadas as falhas que afetam o desempenho do sistema de forma a reduzir as incertezas inerentes ao processo da indústria química [23]. A ferramenta também tem apresentado resultados consideráveis para execução de programas, desde a manufatura aditiva, utilizada no desenvolvimento da impressão de metais até o uso da inteligência artificial [24]. Destaca-se também o uso da ferramenta na indústria da construção civil, demonstrando sua diversidade de aplicação, no que tange a análise de fatores de risco do aumento de custos na construção modular, bem como na identificação de possíveis problemas com o uso de concreto reforçado ou aço [25]. Além disso, por meio da utilização da ferramenta é possível projetar programas de manutenção industrial, vinculando sua aplicação ao conhecimento especializado [24].

Referente a sua utilização prática, vale ainda reforçar a importância da aplicação da ferramenta desde o planejamento inicial de projetos, passando pela definição do problema principal até a verificação de risco e aplicação de ações que evitem problemas graves [25]. Lobo [26], também ressalta a importância da aplicação do método FMEA por engenheiros de segurança do trabalho que buscam analisar as origens de riscos ocorridos nas empresas.

Fogliatto e Ribeiro [27], concluem que o sucesso da técnica normalmente é constatado quando a mesma é aplicada antes das ocorrências de falhas, onde um diagnóstico prévio permite aferir riscos que ainda não estão incorporados ao sistema. Desta forma, o uso planejado da ferramenta pode evitar crises indesejáveis ou mudanças bruscas na operação. Os autores também afirmam que o desenvolvimento de um processo depende do desenvolvimento das experiências em equipe, inerente ao próprio método de utilização da ferramenta.

\section{Metodologia}

A empresa estudada, que por questões éticas não terá seu nome revelado, consiste em uma operadora ferroviária de carga, que atua no mercado logístico por meio de concessões. A empresa atualmente transporta commodities minerais e agrícolas, priorizando fluxos que gerem escala e relações de longo prazo. Esta empresa vem priorizando uma evolução significativa de seus indicadores de segurança, promovendo um impacto positivo quanto ao número de acidentes sem afastamento. Embora esta seja uma realidade, foi verificado que a empresa ainda precisa de auxílio para o aperfeiçoamento de suas atividades, sendo esta a principal condição que deu a oportunidade de acesso ao caso pelos pesquisadores.

A escolha pela utilização da ferramenta FMEA para a realização dos trabalhos se deu pela necessidade de utilização de uma técnica sistemática e organizada de detecção e tratativa de falhas que pudesse auxiliar no desenvolvimento de ações eficientes para os problemas de segurança operacional. A ferramenta foi utilizada com o auxílio dos pesquisadores, gestores e funcionários do setor de manutenção da empresa, para 
avaliar as potencias falhas dos processos que podem resultar em acidentes. Desta forma, no decorrer da pesquisa foram detalhadas as causas e efeitos, bem como as probabilidades e os graus de severidade destes eventos, visando a priorização das atitudes e ações propostas para a resolução dos problemas e garantia da segurança operacional.

Conforme defendido por Lobo [28], as ações de análise devem reunir grupos e representantes das funções do processo para o reconhecimento dos tipos de falhas que ocorrem, seus efeitos, causas, bem como dos controles existentes. A aplicação da ferramenta FMEA contou com a colaboração de 4 envolvidos, em que a análise parcial dos dados ocorreu por meio de informações obtidas de quatro responsáveis: o técnico de manutenção da oficina, o coordenador do setor, o gerente da oficina e o gerente geral da área. As observações foram realizadas a partir da análise das atividades de um grupo de 21 pessoas, compostas por mecânicos, freístas (denominação ao mantenedor mecânico especialista em freios de vagões) e soldadores.

A pesquisa realizada baseou-se em uma abordagem qualitativa, no intuito de compreender como se dão as falhas, dentro do processo de manutenção de uma empresa ferroviária. Lobo [28] afirma, que as falhas de planejamento e execução do processo são obtidas na análise de não conformidades com procedimentos estabelecidos. Nesta circunstância, os dados aqui apresentados foram recolhidos através de observação de desvios dos próprios funcionários e discutidos em conjunto com a gerência no intervalo de eventuais 10 dias. A apresentação destes dados à gerência consistiu em um esforço para garantir a confiabilidade das informações e uma melhor aceitação de sugestões de melhoria.

O foco de observação foi o processo de manutenção de uma oficina de material rodante, onde se destacaram alguns fatos e características das atividades dos envolvidos, as quais são realizadas de forma natural no cotidiano dos mantenedores. A observação foi realizada tanto a distância pelos pesquisadores quanto de forma direta, por meio dos mantenedores do processo. Os períodos de observação ocorreram em horários determinados e foram contempladas todas as equipes que trabalham na oficina em questão. A interpretação possibilitou uma visão mais ampla do trabalho, assim como permitiu vislumbrar algumas estratégias para reduzir o potencial de acidente neste ambiente de trabalho.

Para a determinação da identificação dos fatores de risco do processo e os seus possíveis impactos, a montagem do FMEA se deu inicialmente com a obtenção e identificação de desvios com relação as atitudes operacionais esperadas, indicadas pelos procedimentos. Estes desvios foram seguidos pelas descrições dos modos de falha e pelos efeitos que estes desvios podem gerar. Posteriormente foi determinado o nível crítico, baseado no grau de Severidade (Tabela 1), no índice de Ocorrência (Tabela 2) e no grau de Detecção (Tabela 3).
Estes índices foram definidos de acordo com critérios pré-estabelecidos e adaptados ao problema real, a fim de quantificar e consequentemente avaliar as falhas. Desta forma, foi imprescindível que os três índices fossem atribuídos individualmente para cada falha, sem que o valor de um interferisse no valor de outro.

Para construção da Tabela 1, o critério estabelecido para a determinação do índice de severidade baseou-se nas leis trabalhistas do Brasil [29], refletindo a tratativa diferenciada dada pela Previdência Social a tipos diferentes de acidentes ou questões prejudiciais ao trabalhador e a empresa. Como exemplo, o índice 5 da Tabela 1, que representa o grau máximo de severidade, é proporcional a gravidade de riscos que podem levar o funcionário a óbito.

Tabela 1 - Escala de severidade [29].

\section{Efeito}

\section{Índice de Severidade: Está}

classificação está associada

a probabilidade de uma situação gerar um impacto inesperado.

\begin{tabular}{|c|c|}
\hline $\begin{array}{l}\text { Acidentes que podem } \\
\text { ocasionar morte }\end{array}$ & 5 \\
\hline $\begin{array}{c}\text { Acidentes com lesões } \\
\text { incapacitantes ao } \\
\text { trabalhador }\end{array}$ & 4 \\
\hline $\begin{array}{c}\text { Acidentes com lesões leves } \\
\text { ao trabalhador }\end{array}$ & 3 \\
\hline Danos à propriedade & 2 \\
\hline Incidentes & 1 \\
\hline
\end{tabular}

Já na Tabela 2, o critério utilizado foi a quantidade de dias em que foi observado um determinado desvio, aumentandose o índice de ocorrência conforme a repetição diária de desvios.

\begin{tabular}{|c|c|c|}
\hline $\begin{array}{l}\text { Probabilidade } \\
\text { de Falha }\end{array}$ & $\begin{array}{c}\text { Quantidade de } \\
\text { dias que foram } \\
\text { observados os atos } \\
\text { inseguros }\end{array}$ & $\begin{array}{l}\text { Índice de } \\
\text { Ocorrência }\end{array}$ \\
\hline $\begin{array}{c}\text { Muito Alta: } \\
\text { Comportamentos quase } \\
\text { diários }\end{array}$ & 5 ou Mais & 5 \\
\hline $\begin{array}{c}\text { Alta: } \\
\text { Comportamentos } \\
\text { Persistentes }\end{array}$ & 4 & 4 \\
\hline $\begin{array}{l}\text { Moderada: } \\
\text { Comportamentos } \\
\text { Ocasionais. }\end{array}$ & 3 & 3 \\
\hline $\begin{array}{c}\text { Provável: } \\
\text { Comportamentos Remotos }\end{array}$ & 2 & 2 \\
\hline $\begin{array}{c}\text { Rara: Comportamentos } \\
\text { Raros }\end{array}$ & 1 & 1 \\
\hline
\end{tabular}


Por meio da Tabela 3, busca-se avaliar o índice de detecção por meio da relação entre dois critérios: a distância entre o equipamento e o colaborador no momento de execução das atividades e a habilidade e técnica para a realização desta. Estes critérios permitem avaliar o índice de detecção da falha.

\begin{tabular}{cccc}
\multicolumn{2}{l}{ Tabela 3 - Escala de detecção } & & \\
\hline Detecção & $\begin{array}{c}\text { Critério: } \\
\text { Distância }\end{array}$ & $\begin{array}{c}\text { Critério: } \\
\text { Questionamento }\end{array}$ & $\begin{array}{c}\text { Índice de } \\
\text { Detecção }\end{array}$ \\
\hline Baixa & Sim & Sim & 4 \\
Moderada & Não & Sim & 3 \\
Provável & Sim & Não & 2 \\
Alta & Não & Não & 1 \\
\hline
\end{tabular}

Após a devida classificação dos índices de severidade, ocorrência e detecção, foi-se então calculado o Número de Prioridade de Risco (NRP) priorizando os requisitos de maior importância. Nesse contexto foram propostas pelos estudantes acadêmicos, medidas para auxiliar as decisões gerenciais focadas no cumprimento das normas e leis que garantem uma maior segurança e saúde dos colaboradores. Estas medidas foram levantadas por meio da realização de um "brainstorming", ferramenta de qualidade que tem como objetivo relatar, unir e produzir o maior número de ideias possíveis [30].

\section{Resultados e discussões}

Para o planejamento da aplicação do FMEA foram utilizados os próprios procedimentos operacionais padrões da empresa em estudo, tendo este partido da própria necessidade desta em levantar o nível de concordâncias entre os procedimentos operacionais $\mathrm{e}$ as reais práticas de seus mantenedores. Foi utilizada para estabelecer o índice de severidade do FMEA, uma equipe composta por membros com experiência de campo e funcionários da empresa, sendo este aspecto essencial para uma visão analítica e conceitual das necessidades do estudo. Deve-se então ressaltar a importância da visão técnica e acadêmica para o sucesso da aplicação da ferramenta.

Na etapa de observação houve auxílio tanto da gestão da oficina, quanto de vários mantedores que ajudaram no esclarecimento dos procedimentos, na compreensão dos conceitos essenciais e no entendimento da complexidade da manutenção de vagões. Também se torna importante ressaltar, que em alguns casos o funcionário que auxiliou na obtenção de dados afirmou que houve a resistência de alguns mantenedores no que diz respeito ao auxílio no entendimento das tarefas abordadas. Este fato dificultou a aplicação da ferramenta em sua completude.

Após a obtenção e o estudo dos dados foi elaborado o FMEA contido no Anexo 1 deste artigo. Nesta análise obtevese o índice RPN classificando os riscos de cada requisito.
Através da utilização de um brainstorming, foram identificadas várias formas de garantir que os mantenedores cumpram de forma padronizada as instruções técnicas da empresa para a realização da manutenção de maneira mais produtiva e segura. Neste ponto, constatou-se a necessidade de acompanhamento mais próximo da gestão da oficina, a promoção da conscientização sobre os riscos e o aumento de motivação dos mantenedores.

Com relação às atividades do mecânico, durante a substituição de truques e/ou rodeiros, foram identificados três modos de falha potencial: a não utilização de calços de forma adequada ao manobrar os vagões; a não utilização de extensores para movimentação de carga e o posicionamento debaixo de cargas suspensas. O efeito dessas falhas está relacionado ao risco de deslocamento do componente do material rodante, que pode gerar danos à integridade física dos funcionários, além de problemas relacionados à ergonomia e ao prensamento de membros.

A causa aparente para os problemas normalmente se encontra nos maus hábitos comportamentais e de segurança e no excesso de autoconfiança dos trabalhadores. Para controle do processo a empresa realiza Análises Preliminares de Risco (APRs), mas nem sempre é suficiente. O brainstorming realizado pelos pesquisadores acadêmicos envolvidos propôs algumas ações relacionadas a investimentos tecnológicos na área de segurança, como a instalação de sensores para detectar o posicionamento correto do calço, bem como o acionamento do maquinário somente a partir de sinal de liberação. Estes sensores, também devem ser instalados de forma que os calços só liberem o rodeiro, caso o extensor esteja devidamente posicionado.

Quanto às atividades do freísta (mecânico de freios) o modo de falha potencial está relacionado à substituição dos componentes de freio. Neste caso, ocorre a permanência do freísta abaixo de uma carga suspensa e a descida dessa pode levar o mantenedor a um acidente com morte. Também na realização da retirada de partes do vagão, houve registros de sucatas deixadas no chão, enquanto deveriam ser descartadas nas lixeiras destinadas a elas. Atitudes assim, facilitam a ocorrência de tropeços e quedas, o que pode causar um acidente com lesões leves ao trabalhador.

Durante as manutenções corretivas e preventivas, houve vários relatos de ferramentas em lugares inadequados, deixando os carrinhos de ferramenta sem utilização. Os riscos eminentes dessas falhas facilitam a possibilidade de queda de ferramentas sobre membros inferiores dos mantenedores, além de tropeços e quedas quando colocadas em áreas indevidas de circulação. Também é ressaltada aqui a falta de isolamento do vagão para a troca de válvulas e do coletor de pó, no qual há risco de perda de membros por parte dos mantenedores.

As ações previstas para controle destas falhas estão contidas em treinamentos e estão disponíveis nos procedimentos 
padrões, os quais apresentam insuficiência na clareza dos riscos relacionados à segurança. Dessa forma o estudo sugere adaptações destes procedimentos, reforçando a importância e mostrando os impactos da não conferência de ar nos vagões, antes de proceder sem o isolamento.

As atividades desenvolvidas pelo soldador apresentaram um modo de falha potencial no que tange a realização da soldagem na estrutura do vagão. Neste caso, durante a movimentação da máquina de solda, esta é arrastada com os cabos soltos, percorrendo a linha de manutenção, quando estes deveriam estar enrolados. Também é necessário destacar a utilização indevida de cabos em condições precárias de isolamento. Além disso, foi identificado durante a soldagem nas estruturas do vagão um risco considerável aos trabalhadores presentes no ambiente, uma vez que não são posicionados os biombos de forma a limitar a fuga das faíscas e fumos de solda oriundas do processo. Esses fatores são causados pela falta de conhecimento por parte dos operadores, sobre os danos que a exposição ao processo de soldagem pode gerar, além de muitas vezes ser relatada a necessidade de se realizar o serviço com rapidez.

$\mathrm{Na}$ movimentação dos equipamentos de solda é obrigatória a utilização de luvas de proteção, no entanto os operadores não fazem este uso. As ações de controle são as mesmas já relatadas para os mecânicos e freístas, o que leva a uma maior desconfiança quanto à eficiência do monitoramento. Desta forma, recomenda-se a utilização de um biombo dobrável e de fácil manuseio que cubra totalmente o operador, oferecendo segurança para o ambiente e seus trabalhadores. Quanto aos cabos espalhados pela linha de manutenção, a disposição de mais tomadas pela área pode minimizar este risco.

Diante dessas colocações, foram identificados através do índice NPR, os riscos de falhas que precisam ser mitigados. Neste caso, o ponto mais crítico está na substituição de truques e rodeiros, bem como dos componentes de freio.

\section{Conclusões}

A partir do desenvolvimento deste trabalho foi possível adquirir um conhecimento aprofundado da aplicação da ferramenta FMEA. A técnica possibilitou a obtenção de um resultado satisfatório para o trabalho desenvolvido e ainda ressaltou a importância de se priorizar uma análise que tenha como objetivo as falhas de segurança do processo. Portanto foi possível identificar que os procedimentos de segurança necessitam de maiores detalhes sobre os riscos que acarretam seu descumprimento. Assim após verificar os procedimentos de segurança já adotados na empresa, mudanças são indispensáveis, tanto nos métodos de prevenção quanto nas formas de monitoramento.

Dos resultados encontrados, obteve-se êxito em levantar as práticas inseguras nas atividades dos mecânicos, soldadores e freístas, não estando estas isentas a riscos de segurança. Dentre as atividades que apresentaram práticas de risco mais relevantes, pode-se observar a substituição de truques e/ou rodeiros, a substituição dos componentes de freio, a realização de retirada de partes do vagão e a realização da soldagem na estrutura do vagão. Deve-se destacar que segundo o método aplicado, os mecânicos tem um maior risco de se acidentar dentro da oficina estudada.

Como achado da pesquisa, evidenciamos a necessidade constante de criar soluções que possam assegurar a integridade física dos mantenedores. Tais soluções devem atender as práticas de troca de truques e/ou rodeiros, componentes de freio e sistema de choque tração para evitar acidentes.

Com o desenvolvimento do trabalho foi possível alertar a gestão sobre algumas falhas do sistema e comprovar que a ferramenta FMEA é de suma importância para o desenvolvimento e aumento da confiabilidade do processo. Assim, ao apresentar o estudo para os membros responsáveis em avaliar a tendência de ocorrência de acidentes na empresa, o método foi julgado como eficiente nas análises de desvios de segurança, ficando compreendida a necessidade urgente de programar melhorias no setor. Porém, esta ferramenta deve ser aplicada continuamente obedecendo assim critérios de qualidade, para que alcance benefícios importantes no serviço final.

Ainda que tenha havido uma evolução na segurança do trabalho no Brasil como já apresentado e que a empresa adote normas e crie programas próprios para conscientizar os trabalhadores, deixa-se então como proposta para trabalhos futuros, uma investigação das reais motivações que levam os funcionários ao descumprimento dos procedimentos da empresa, uma vez que, segundo Knapik [26], as organizações devem tratar o ser humano como uma variável complexa de um processo.

\section{Agradecimentos}

Agradeço a André Luiz Gabriel Henriques por ser um exemplo de líder auxiliador e ao IFMG-campus Congonhas pelo estímulo.

\section{PROPOSITION OF SAFETY IMPROVEMENTS THROUGH THE APPLICATION OF FMEA: A CASE STUDY IN A RAILROAD COMPANY.}

ABSTRACT: This paper presents a case study about Failure Modes and Effects Analysis (FMEA) tool application in a railway company with the objective of raising the main insecure practices in wagons maintenance. For this purpose, the approach adopted here included a historical review of safety work evolution and maintenance in Brazil, as well as the use of FMEA in service practices. From FMEA application, an analysis of 
unsafe activities in company wagons maintenance was carried out, identifying risk functions and proposing improvements that Might be be implemented. The results identified critical points of failure inside process, which can then be analyzed to determine improvement strategies in order to maximize worker safety and ensure service reliability. It was concluded that FMEA tool is useful for mapping attitudes that threaten the physical integrity of the worker and that behavior is the most important point to be addressed in work safety proposals.

Key words: work safety; FMEA; maintenance.

\section{Referências}

[1]TSENG, Y.; YUE, W. L.; TAYLOR, M. A. P. The role of transportation in logistics chain. Eastern Asia Society for Transportation Studies, v. 5, p. 16571672,2005

[2]VENCOVSKY, Vitor Pires. Ferrovia e logística do agronegócio globalizado: Avaliação das políticas públicas e privadas do sistema ferroviário brasileiro, 2011. 198f. 2011. Tese de Doutorado. Tese (Doutorado em Geografia). Instituto de Geociências. Universidade Estadual de Campinas (Unicamp).

[3]KARDEC, Alan; NASCIF, Júlio. Manutenção: Função Estratégica. $3^{a}$ ed. Rio de Janeiro. Qualitymark, 2009.

[4]NEPOMUCENO, L. X. Técnicas de manutenção preditiva. São Paulo: Blucher, 1989, V. 1.

[5] ABNT - Associação Brasileira de Normas Técnicas. NBR ISSO 55000: Gestão de ativos- Visão geral, princípios e terminologia. Rio de Janeiro: ABNT, 2014.

[6] SELEME, Robson. Manutenção industrial: mantendo a fábrica em funcionamento. Curitiba: Inter saberes. 2015

[7] KARDEC, A. NASCIF, J. Manutenção: função estratégica. 4. Ed. Rio de Janeiro: Qualitymark, 2013.

[8] FREITAS, Luís Conceição. Manual de segurança e saúde do trabalho. Sílabo, 2008.

[9] KARDEC, Alan; NASCIF, Júlio; BARONI, Tarcísio. Gestão Estratégica e Técnicas Preditivas. Rio de Janeiro. Qualitymark, 2007.

[10] CHAGAS, Ana Maria de Resende; SALIM, Celso Amorim; SERVO, Luciana Mendes Santos. Saúde e segurança no trabalho no Brasil: aspectos institucionais, sistemas de informação e indicadores. 2011.

[11] OLIVEIRA, S. Estrutura normativa da segurança e saúde do trabalhador no Brasil. Rev. Trib. Reg. Trab. 3a Reg., Belo Horizonte, v. 45, n. 75, p. 107-130, jan./jun. 2007.

[12] ALVES, R. R. et al. Projeto oficina modelo: Avaliação dos Resultados obtidos após implantação do Projeto Oficina Modelo numa oficina de manutenção de vagões localizada em Barra do Pirai. Revista EpistemeTransversalis. Volta Redonda-RJ. vol. 10, p. 139-16, 2016.

[13] BRASIL. Lei ${ }^{\circ} 6.514$, de 22 de dezembro de 1977. Altera o Capítulo V do Título II da Consolidação das Leis do Trabalho, relativo a segurança e medicina do trabalho, e dá outras providências. Diário Oficial da União, 1977.
[14] BRASIL, Portaria GM. n. ${ }^{\circ}$ 3.214, de 08 de junho de 1978. NR-1, Disposições Gerais, Brasília, v. 6, 1978.

[15] BITENCOURT, Celso Lima; QUELHAS, Osvaldo Luis Gonçalves. Histórico da evolução dos conceitos de segurança. Encontro Nacional de Engenharia de Produção, v. 18, 1998.

[16] MIGUEL, Alberto Sérgio. Manual de Higiene e Segurança no Trabalho. 11 Edição. Porto: Porto Editora, 2010.

[17] OLIVEIRA, Fábio de. A persistência da noção de ato inseguro e a construção da culpa: os discursos sobre os acidentes de trabalho em uma indústria metalúrgica. Revista Brasileira de Saúde Ocupacional, v. 32, n. 115, 2007.

[18] Ministério do Trabalho (BR). Portaria $\mathrm{n}^{\circ}$ 84/09, de 04 de março de 2009. Altera a redação do item 1.7 da Norma Regulamentadora $n .^{\circ} 1$ no que se refere às competências da União, estados, municípios e Distrito Federal, na área de Inspeção do trabalho, define a devida redação e dá outras providências. Diário Oficinal União. 12 mar. 2009; Pág.64

[19] REASON, J.T. Human Error. Cambridge: Cambridge University Press, 1990.

[20] DE OLIVEIRA, Leandro Nascimento; DE FREITAS, Lucia Santana. O uso do FMEA como ferramenta de avaliação dos aspectos e impactos ambientais numa indústria de microeletrônica. Revista Gestão Industrial, v. 9, n. 4, 2014.

[21] BRADLEY, James R.; GUERRERO, Héctor H. An alternative FMEA method for simple and accurate ranking of failure modes. Decision Sciences, v. 42, n. 3, p. 743-771, 2011.

[22] FOGLIATTO, Flávio Sanson; RIBEIRO, José Luis Duarte. Confiabilidade e Manutenção Industrial. Ed. 1. Rio de Janeiro-RJ: Elsevier, 2009.

[23] AHN, Junkeon et al. Fuzzy-based failure mode and effect analysis (FMEA) of a hybrid molten carbonate fuel cell (MCFC) and gas turbine system for marine propulsion. Journal of Power Sources, v. 364, p. 226-233, 2017.

[24] PEETERS, J. F. W.; BASTEN, R. J. I.; TINGA, Tiedo. Improving failure analysis efficiency by combining FTA and FMEA in a recursive manner. Reliability engineering \& system safety, v. 172, p. 36-44, 2018.

[25] LEE, Jae-Seung; KIM, Yea-Sang. Analysis of cost-increasing risk factors in modular construction in Korea using FMEA. KSCE Journal of Civil Engineering, v. 21, n. 6, p. 1999-2010, 2017.

[26] LOBO, Renato Nogueirol. Gestão da qualidade. São Paulo: Érica, 2010, p.143-146.

[27] OLIVEIRA, Juliano Acioly; SCHOLZ, Robinson Henrique. Transporte Ferroviário: do auge ao abandono, e a perspectiva de crescimento do sistema ferroviário de carga no brasil. SEFIC 2015, 2017.

[28] RAWLINSON, J. Geoffrey. Creative thinking and brainstorming. Routledge, 2017.

[29] BRASIL. Lei n. 8.213, de 24 de julho de 1991. Dispõe sobre os Planos de Benefícios da Previdência Social e dá outras providências.

[30] KNAPIK, Janete. Gestão de pessoas e talentos. Editora Ibpex, 2008. 
ANEXO 1- Representação dos formulários da ferramenta FMEA desenvolvidos.

\begin{tabular}{|c|c|c|c|c|c|c|c|c|c|c|}
\hline $\begin{array}{lr}\text { Função do } \\
\text { Processo e } \\
\text { Requisitos }\end{array}$ & $\begin{array}{l}\text { Modo de } \\
\text { Falha } \\
\text { Potencial }\end{array}$ & $\begin{array}{l}\text { Efeito(s) } \\
\text { Potencial(is) } \\
\text { da Falha(s) }\end{array}$ & 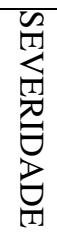 & $\begin{array}{l}\text { Causa(s) e } \\
\text { Mecanismo(s) } \\
\text { Potencial(is) } \\
\text { da Falha(s) }\end{array}$ & 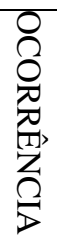 & $\begin{array}{ll}\text { Controles } & \\
\text { Atuais } & \text { do } \\
\text { Processo } & \\
\text { Prevenção } & \end{array}$ & $\begin{array}{ll}\text { Controles } & \\
\text { Atuais do } & \text { do } \\
\text { Processo } & \\
\text { Detecção } & \end{array}$ & 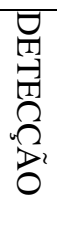 & $\underset{Z}{Z}$ & $\begin{array}{l}\text { Ações } \\
\text { recomendadas }\end{array}$ \\
\hline $\begin{array}{l}\text { Substituição } \\
\text { de truques } \\
\text { ou/e } \\
\text { Rodeiros. }\end{array}$ & $\begin{array}{l}\text { A Não } \\
\text { utilização } \\
\text { de calços } \\
\text { de forma } \\
\text { adequada }\end{array}$ & $\begin{array}{l}\text { Risco de } \\
\text { deslocamento } \\
\text { do componente } \\
\text { do material } \\
\text { rodante, } \\
\text { podendo } \\
\text { causar à } \\
\text { prejuízos an dos } \\
\text { integridade } \\
\text { física } \\
\text { mantenedores. }\end{array}$ & 4 & $\begin{array}{l}\text { Maus hábitos e } \\
\text { excesso de } \\
\text { autoconfiança. }\end{array}$ & 5 & $\begin{array}{l}\text { Análise } \\
\text { Preliminar de } \\
\text { Risco }\end{array}$ & $\begin{array}{l}\text { Inspeções } \\
\text { gerenciais e de } \\
\text { coordenadoria }\end{array}$ & 4 & 80 & $\begin{array}{l}\text { Colocar sensor } \\
\text { para detectar se } \\
\text { o calço está } \\
\text { devidamente } \\
\text { encaixado e } \\
\text { através de sinal, } \\
\text { liberar o } \\
\text { acionamento do } \\
\text { maquinário. }\end{array}$ \\
\hline $\begin{array}{l}\text { Substituição } \\
\text { de truques } \\
\text { ou/e } \\
\text { Rodeiros. }\end{array}$ & $\begin{array}{l}\text { A não } \\
\text { utilização } \\
\text { de } \\
\text { extensores } \\
\text { para } \\
\text { moviment } \\
\text { ação de } \\
\text { carga. }\end{array}$ & $\begin{array}{l}\text { Riscos de } \\
\text { problemas } \\
\text { ergonômicos } \\
\text { e prensamento } \\
\text { de membros. }\end{array}$ & 3 & $\begin{array}{lr}\text { Os } \\
\text { mantenedores } \\
\text { relatam a } \\
\text { facilidade em } \\
\text { empurrar } & \text { os } \\
\text { rodeiros com } \\
\text { as mãos, ao } \\
\text { invés } \\
\text { utilizar de } \\
\text { extensores. }\end{array}$ & 5 & $\begin{array}{l}\text { Desenvolvimento } \\
\text { de treinamentos; } \\
\text { Disponibilização } \\
\text { de extensores de } \\
\text { forma simples e } \\
\text { acessível; }\end{array}$ & $\begin{array}{l}\text { Líder, } \\
\text { apadrinhament } \\
\text { o e câmeras. }\end{array}$ & 3 & 45 & 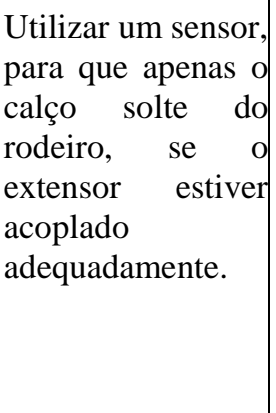 \\
\hline $\begin{array}{l}\text { Soldadores } \\
\text { realizando } \\
\text { solda na } \\
\text { estrutura do } \\
\text { vagão. }\end{array}$ & $\begin{array}{l}\text { Uso de } \\
\text { equipamen } \\
\text { to com os } \\
\text { cabos dos } \\
\text { equipamen } \\
\text { tos sem } \\
\text { proteção. }\end{array}$ & $\begin{array}{l}\text { Risco } \\
\text { choque } \\
\text { elétrico. }\end{array}$ & 2 & $\begin{array}{l}\text { Foi observado } \\
\text { que na } \\
\text { movimentação } \\
\text { de máquinas } \\
\text { em diversas } \\
\text { vezes, os } \\
\text { mantenedores } \\
\text { passam com } \\
\text { rodas por cima } \\
\text { de fios de } \\
\text { outros } \\
\text { equipamentos. }\end{array}$ & 2 & $\begin{array}{ll}\text { Procedimento } & \mathrm{de} \\
\text { manuseio } & \mathrm{de} \\
\text { máquina } & \mathrm{de} \\
\text { solda. } & \end{array}$ & $\begin{array}{l}\text { Técnico de } \\
\text { segurança do } \\
\text { Trabalho, } \\
\text { Líder, } \\
\text { Inspeções } \\
\text { gerenciais e de } \\
\text { coordenadores } \\
\text {. }\end{array}$ & 2 & 8 & $\begin{array}{l}\text { Criar advertência, } \\
\text { por não cumprir } \\
\text { procedimento da } \\
\text { área. }\end{array}$ \\
\hline
\end{tabular}




\begin{tabular}{|c|c|c|c|c|c|c|c|c|c|c|}
\hline $\begin{array}{l}\text { Função do } \\
\text { Processo e } \\
\text { Requisitos }\end{array}$ & $\begin{array}{l}\text { Modo de } \\
\text { Falha } \\
\text { Potencial }\end{array}$ & $\begin{array}{l}\text { Efeito(s) } \\
\text { Potencial } \\
\text { (is) da } \\
\text { Falha(s) }\end{array}$ & 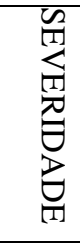 & $\begin{array}{l}\text { Causa(s) e } \\
\text { Mecanismo(s) } \\
\text { Potencial(is) da } \\
\text { Falha(s) }\end{array}$ & $\begin{array}{l}0 \\
0 \\
0 \\
0 \\
\mathbb{2} \\
2 \\
\Omega\end{array}$ & $\begin{array}{l}\text { Controles } \\
\text { Atuais do } \\
\text { Processo } \\
\text { Prevenção }\end{array}$ & $\begin{array}{l}\text { Controles } \\
\text { Atuais do } \\
\text { Processo } \\
\text { Detecção }\end{array}$ & $\overbrace{0}^{\theta}$ & $\underset{Z}{Z}$ & $\begin{array}{l}\text { Ações } \\
\text { recomenda } \\
\text { das }\end{array}$ \\
\hline $\begin{array}{l}\text { Substituição } \\
\text { de } \\
\text { componentes } \\
\text { de Freio. }\end{array}$ & $\begin{array}{lr}\text { Não Isolar o } \\
\text { vagão } & \text { para } \\
\text { troca } & \text { de } \\
\text { válvula } & \text { e } \\
\text { coletor } & \text { de } \\
\text { pó. } & \end{array}$ & $\begin{array}{l}\text { Risco de } \\
\text { perdas de } \\
\text { membros. }\end{array}$ & 4 & $\begin{array}{lr}\text { Os Freístas } \\
\text { relataram não } \\
\text { verem a } \\
\text { necessidade de } \\
\text { se isolar o } \\
\text { vagão, se não } \\
\text { houver ar e se o } \\
\text { equipamento de } \\
\text { análise de freio, } \\
\text { não estiver } \\
\text { ligado. }\end{array}$ & 5 & $\begin{array}{l}\text { Treinamento do } \\
\text { procedimento }\end{array}$ & Auditorias. & 4 & 80 & $\begin{array}{l}\text { Sugiro } \\
\text { alterações do } \\
\text { Procedimento } \\
\text { Operacional. }\end{array}$ \\
\hline $\begin{array}{l}\text { Substituição } \\
\text { de rodeiros } \\
\text { e/ou truque. }\end{array}$ & $\begin{array}{l}\text { Permaneceu } \\
\text { em baixo do } \\
\text { vagão com o } \\
\text { macaco } \\
\text { descendo. }\end{array}$ & $\begin{array}{l}\text { Bater com } \\
\text { a cabeça na } \\
\text { estrutura } \\
\text { do vagão. }\end{array}$ & 5 & $\begin{array}{ll}\text { Necessidade } & \text { de } \\
\text { rapidez } & \text { no } \\
\text { serviço. } & \end{array}$ & 3 & $\begin{array}{l}\text { Análise } \\
\text { Preliminar } \\
\text { de Risco }\end{array}$ & $\begin{array}{l}\text { Técnico de } \\
\text { segurança } \\
\text { do } \\
\text { Trabalho e } \\
\text { Líder. }\end{array}$ & 2 & 30 & $\begin{array}{l}\text { Acrescentar } \\
\text { sensor no } \\
\text { macaco } \\
\text { hidráulico, } \\
\text { para que não } \\
\text { desça a } \\
\text { estrutura do } \\
\text { vagão com } \\
\text { pessoas } \\
\text { embaixo. }\end{array}$ \\
\hline $\begin{array}{l}\text { Realização } \\
\text { de Solda na } \\
\text { estrutura do } \\
\text { Vagão. }\end{array}$ & $\begin{array}{l}\text { Usou } \\
\text { incorreto de } \\
\text { Biombo. }\end{array}$ & $\begin{array}{l}\text { Queimadura } \\
\text { s na pele e } \\
\text { problemas } \\
\text { oculares. }\end{array}$ & 1 & $\begin{array}{l}\text { Falta de } \\
\text { conhecimento } \\
\text { sobre os } \\
\text { prejuízos que a } \\
\text { exposição a } \\
\text { partículas e a } \\
\text { fumos pode } \\
\text { causar. }\end{array}$ & 5 & $\begin{array}{l}\text { Alto número } \\
\text { de Biombos, } \\
\text { disponíveis } \\
\text { na área. }\end{array}$ & $\begin{array}{l}\text { Técnico de } \\
\text { segurança } \\
\text { do } \\
\text { Trabalho e } \\
\text { Líder. }\end{array}$ & 1 & 5 & $\begin{array}{l}\text { Criar um } \\
\text { biombo } \\
\text { dobrável e } \\
\text { de fácil } \\
\text { manuseio, } \\
\text { para cobrir } \\
\text { totalmente o } \\
\text { soldador. }\end{array}$ \\
\hline
\end{tabular}




\begin{tabular}{|c|c|c|c|c|c|c|c|c|c|c|}
\hline $\begin{array}{l}\text { Função do } \\
\text { Processo } \\
\text { Requisitos }\end{array}$ & $\begin{array}{l}\text { Modo de } \\
\text { Falha } \\
\text { Potencial }\end{array}$ & $\begin{array}{l}\text { Efeito(s) } \\
\text { Potencial (is) } \\
\text { da Falha (s) }\end{array}$ & 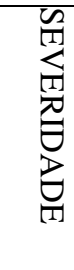 & $\begin{array}{l}\text { Causa(s) e } \\
\text { Mecanismo } \\
\text { (s) } \\
\text { Potencial } \\
\text { (is) da } \\
\text { Falha(s) }\end{array}$ & 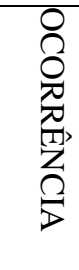 & $\begin{array}{l}\text { Controles } \\
\text { Atuais do } \\
\text { Processo } \\
\text { Prevenção }\end{array}$ & $\begin{array}{l}\text { Controles } \\
\text { Atuais do } \\
\text { Processo } \\
\text { Detecção }\end{array}$ & ת̃ & $\frac{Z}{\bar{z}}$ & $\begin{array}{l}\text { Ações } \\
\text { recome } \\
\text { ndadas }\end{array}$ \\
\hline $\begin{array}{l}\mathrm{Na} \\
\text { realização } \\
\text { tanto das } \\
\text { manutenções } \\
\text { corretivas } \\
\text { quanto das } \\
\text { preventivas. }\end{array}$ & 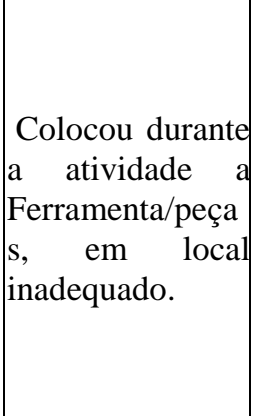 & $\begin{array}{l}\text { Risco de } \\
\text { quedas de } \\
\text { ferramentas } \\
\text { sobre o } \\
\text { mantenedor, } \\
\text { além de criar } \\
\text { um ambiente } \\
\text { que facilite } \\
\text { tropeços e } \\
\text { quedas. }\end{array}$ & 3 & $\begin{array}{l}\text { Maus } \\
\text { hábitos e } \\
\text { desânimo } \\
\text { para buscar } \\
\text { os suportes. }\end{array}$ & 5 & Treinamentos & $\begin{array}{l}\text { Líder, } \\
\text { Auditorias e } \\
\text { apadrinhamento } \\
\text {. }\end{array}$ & 1 & 15 & 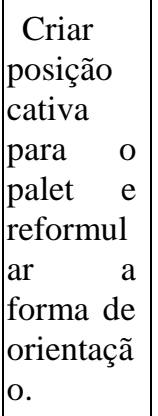 \\
\hline $\begin{array}{l}\text { Os } \\
\text { soldadores } \\
\text { realizando } \\
\text { manutenção } \\
\text { da estrutura } \\
\text { do vagão. }\end{array}$ & $\begin{array}{l}\text { Movimentação } \\
\text { de máquinas } \\
\text { de solda, } \\
\text { arrastando os } \\
\text { cabos na linha. }\end{array}$ & $\begin{array}{l}\text { Risco de } \\
\text { tropeços } \\
\text { desgaste dos } \\
\text { fios, podendo } \\
\text { criar riscos de } \\
\text { choques } \\
\text { elétricos. }\end{array}$ & 4 & $\begin{array}{l}\text { Movimentaçã } \\
\text { o } \\
\text { máquinas de } \\
\text { solda entre as } \\
\text { linhas. }\end{array}$ & 1 & $\begin{array}{l}\text { Instrução em } \\
\text { DDS }\end{array}$ & $\begin{array}{lr}\text { Técnico } & \text { de } \\
\text { segurança } & \text { do } \\
\text { Trabalho } & \text { e } \\
\text { Líder. } & \end{array}$ & 2 & 8 & $\begin{array}{ll}\text { Determin } \\
\text { ação } & \text { de } \\
\text { lugares } \\
\text { cativos } & \text { e } \\
\text { fixos } & \text { para } \\
\text { as } \\
\text { máquinas } \\
\text { de solda. }\end{array}$ \\
\hline $\begin{array}{l}\text { Realização } \\
\text { de retiradas } \\
\text { de partes do } \\
\text { vagão para } \\
\text { manutenção. }\end{array}$ & $\begin{array}{l}\text { Após a } \\
\text { realização do } \\
\text { trabalho } \\
\text { deixou sucatas } \\
\text { no chão. }\end{array}$ & $\begin{array}{l}\text { Risco de } \\
\text { choque } \\
\text { elétrico. }\end{array}$ & 2 & \begin{tabular}{l}
\multicolumn{2}{c|}{ Foi } \\
observado \\
que na \\
movimentaçã \\
o de \\
máquinas, em \\
diversas \\
vezes, os \\
mantenedore \\
s passam com \\
rodas sobre o \\
cabeamento.
\end{tabular} & 2 & \begin{tabular}{l}
\multicolumn{2}{c}{ Procediment } \\
o de \\
manuseio \\
máquina \\
solda.
\end{tabular} & $\begin{array}{l}\text { Técnico de } \\
\text { segurança do } \\
\text { Trabalho, Líder, } \\
\text { Inspeções } \\
\text { gerenciais e de } \\
\text { coordenadoria. }\end{array}$ & 2 & 8 & $\begin{array}{l}\text { Criação } \\
\text { de mais } \\
\text { lixeiras na } \\
\text { oficina } \\
\text { para } \\
\text { facilitar o } \\
\text { descarte } \\
\text { de sucata. }\end{array}$ \\
\hline
\end{tabular}

